\title{
Case Report: Successful Treatment of Acute Aluminum Phosphide Poisoning by Aloe Vera Syrup: A Case Report
}

\author{
Masihallah Shakeri ${ }^{1}$ (D), Davood Soroosh ${ }^{2}$, Heshmatollah Shakeri ${ }^{1}$, Navid Kalani ${ }^{3 *}$ (D, Naser Hatami ${ }^{4}$, Mahdi Foroughian $^{5}$
}

1. Department of Internal Medicine, School of Medicine, Jahrom University of Medical Sciences, Jahrom, Iran.

2. Department of Internal Medicine, School of Medicine, Sabzevar University of Medical Sciences, Sabzevar, Iran.

3. Research Center for Social Determinants of Health, Jahrom University of Medical Sciences, Jahrom, Iran.

4. Student Research Committee, Jahrom University of Medical Sciences, Jahrom, Iran.

5. Department of Emergency Medicine, School of Medicine, Mashhad University of Medical Sciences, Mashhad, Iran.

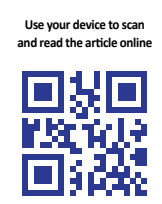

Citation: Shakeri M, Soroosh D, Shakeri H, Kalani N, Hatami N, Foroughian M. Successful Treatment of Acute Aluminum Phosphide Poisoning by Aloe Vera Syrup: A Case Report. International Journal of Medical Toxicology and Forensic Medicine. 2021; 11(2):33016. https://doi.org/10.32598/ijmtfm.v11i2.33016

https://doi.org/10.32598/ijmtfm.v11i2.33016

Article info:

Received: 27 Nov 2020

First Revision: 10 Dec 2020

Accepted: 13 Dec 2020

Published: 15 Jun 2021

\section{A B S T RACT}

Background: Aluminum phosphide, known as rice pill in Iran, is a very effective pesticide for commercial and industrial use. The high lethality of Aluminum phosphide is due to Phosphine gas (PH3) which is released by its reaction with water. One of the most important properties of aluminum phosphide, which despite being very lethal to almost all living creatures, still makes it one of the most widely used pesticides, is its very high yield, ease of use, and, most importantly, the absence of residues in products after application; while its exposure to the human body is associated with high mortality.

Case Presentation: In this article, we reported the successful treatment of rice pill-induced poisoning in a 30-year-old man using a novel approach. Accordingly, we used sodium bicarbonate $(50 \mathrm{ccs})$ and aloe vera syrup (1-2 L), followed by olive oil (150 cc olive oil was given every 2 hours).

Conclusion: While numerous studies recommend observing patient conditions as the treatment approach, our presented case was a successful experience of treating acute aluminum phosphide poisoning.
Aluminum phosphide, Poisoning, Aloe vera tablets or powder coatings [2]. Eating AlP is a very common method of poisoning [3]. Exposure to phosphine vapors and powdery mildew are other ways of contamination [4]. This toxic compound was first marketed in India. There exist numerous reports of intentional or accidental intoxication with up to 1500 cases a year in India; two-thirds of which result in death [5]. Iran statistics also present the high prevalence and increasing use

shades of yellowis

* Corresponding Author:

Navid Kalani, PhD.

Address: Research Center for Social Determinants of Health, Jahrom University of Medical Sciences, Jahrom, Iran.

Tel: +98 (917) 5605412

E-mail: navidkalani@ymail.com 
of youth in this fatal poison [6]. Rice pills poisoning was the essential cause of severe poisoning and leading to death, especially in Iran in recent years, with a mortality rate of up to $60 \%[6,7]$. AlP is inexpensive and highly effective against rodents; therefore, it is widely used in developing countries [8]. Although the drug is not legally available in Iran, it is brought into the country and marketed in herbal remedies stores [9]. This poisoning mostly occurs at a young age. Besides, its various social, cultural, geographical, and availability factors have exacerbated the deterioration of liability [10]. The advantages of using phosphides are their low cost, easy application, and high cost-effectiveness. After taking this toxin, the phosphine gas is released in the presence of gastric acid, i.e. rapidly absorbed through the digestive tract and leads to systemic toxicity in the body [12]. Unfortunately, an early diagnosis of poisoning is impossible in the early hours and is solely based on the observation of clinical signs and symptoms [13]. The clinical findings in nonspecific poisoning are complicated by the dose, the route of use, and time elapsed after the toxicant [14]. Most of the toxicities, like AlP poisoning are confirmed after 24 hours of hemoglobin measurement [15]. The precise mechanism of the effects of AlP remains unclear in individuals. Furthermore, severe cellular damage is a major action mechanism of AlP. Furthermore, it does not involve a single organ, leading to multiple organ failure [16]. The effects of poisoning include damages to the heart, lungs, kidneys, and liver, as well as symptoms, such as cardiac arrhythmias, acidosis, and pulmonary edema $[17,18]$. Heart failure, arrhythmia, seizures, coma, and the delayed onset of liver and kidney toxicity may also occur [18]. Phosphine gas is colorless and odorless. There are no specific treatment interventions for phosphine gas poisoning; numerous patients fail to survive from such conditions [19].

Aloe vera is among the major medicinal herbal species, i.e. mostly found in hot and humid regions. Aloe vera has various therapeutic effects. In recent years, it has attracted the attention of extensive researchers. Active compounds in the aloe vera gel include aloe, amrodine, aloe vera amrodine, barberaluin, zeolite, and monosaccharides, such as sterols, allic acids, as well as vitamins B and C [20]. It has been contributed to various therapeutic effects as well as impacts on the immune system, laxative effects, antiviral and antitumor activities, moisturizing and anti-aging effects, antiseptic effects, and healing properties [20]. Previous studies documented the potential effects of aloe vera in treating various toxicities in animal models. Aloe vera in AlP-exposed rats prevented renal damage [21]. Additionally, attractive studies have been conducted in the field of bio-engineering, where aloe vera was observed to block the surface-active sites of metals, particularly by the tan- nin compound of aloe vera [22]. Thus, this study aimed to evaluate the effect of aloe vera as an adjuvant in the AlP intoxication treatment. Here, we presented our successful approach to AlP intoxication treatment.

\section{Case Presentation}

A 30-year-old man was admitted to Motahari Hospital in Jahrom City, Iran at 3:51 pm with his brother. He stated that he had taken three pills of AlP. The patient was conscious of the time, place, and he was vomiting constantly. The patient's initial vital signs were Blood Pressure (BP):70/40, PR: 70, 95\% $\mathrm{O}_{2}$ SAT, and complained of abdominal pain. The patient's Electrocardiogram (ECG) was normal but the patient presented metabolic acidosis (PH: 7.04, $\left.\mathrm{HCO}_{3}: 12, \& \mathrm{PaCo}_{2}: 36\right)$. All other biochemical tests presented normal data.

Immediately, a normal saline intravenous fluid bolus was administered for the patient. The patient was first rinsed with sodium bicarbonate $(50 \mathrm{cc})$ and aloe vera syrup (1-2 L), followed by olive oil (150 cc olive oil was given every $2 \mathrm{~h}$ ). Charcoal was then given with NAC (N-acetylcysteine), calcium gluconate, as well as glucose and insulin. The patient developed hypotension, i.e. returned to baseline by the administration of normal saline bolus and $50 \mathrm{cc}$ dextrose $50 \%+6$ units of regular insulin. Additionally, the patient was given bicarbonate intravenously $(50 \mathrm{cc}$ ) and orally $(50 \mathrm{cc})$. Next, the patient was transferred to the Intensive Care Unit (ICU). In the ICU, he continued complaining of abdominal pain. Then, the patients' consciousness level suddenly declined. The patient also presented diarrhea and the olive oil administration was immediately stopped.

On day 2 in the ICU, calcium gluconate and NAC dose were reduced and charcoal, as well as glucose and insulin, were discontinued. The level of consciousness increased in the patient. The patient was ill; however, he was oriented to time and place. The patient's abdominal pain decreased, accordingly. The patient also felt hungry and the fluid regimen began immediately.

On day 3 in the ICU, N-Acetyl Cysteine (NAC) was discontinued. One effervescent calcium pill was given orally to the patient. Pantoprazole tablets were administered to the patient one per morning and night. The patient was transferred from the ICU bed to the inpatient ward. On day 4, psychiatric consultation was performed and the patient's 24-hour IV therapy was reduced. On day 5, the patient regained full consciousness and provided normal vital signs, and was discharged from the hospital. 


\section{Discussion}

The presented case was a successful experience of AlP poisoning treatment following intoxication with 3 pills. The treatment approached used for the presented case was previously applied by Rayat Dost and associates [20]. Singh et al. found that in patients with AlP poisoning, the pressure drop is often so severe that continuous administration of isotonic serum is insufficient and using dopamine is inevitable. Accordingly, to overcome bradycardia, continuous injection of sodium bicarbonate is required [22]. In our study, sodium bicarbonate was used to relieve blood pressure on the first day before the patient was admitted to the ICU. Karimi et al. argued that acidosis complicates this proves and sometimes makes it impossible to reduce patient's cardiovascular arrhythmias. The types of cardiac arrhythmias caused by the direct effect of the drug on the heart and by acidosis and hypotension are the leading causes of death in the early hours after poisoning. Vital signs, blood gas control, $\mathrm{pH}$, cardiac monitoring, and a continued presence of physicians and nurses at the bedside of the patient are essential for their wellbeing. Therefore, transferring patients to the ICU is a key element in the remission process [23].

This was similar to the treatment approach in our study of the patient's treatment, especially in the first 3 days. Siwach et al. emphasized the use of calcium and magnesium in this respect. They suggested magnesium sulfate treatment, because of the high prevalence of hypomagnesemia during AlP poisoning and its association with lethal arrhythmias and death [24]. In our study, similar to the investigation by Siwach et al., the administration of calcium was continued until the patient's condition improved (first 3 days). Schonwald reported that repeated gavage of sorbitol and mineral oils were useful in preventing phosphide release and accelerating excretion [25]. Similar to the one in our study, the first day after the patient's gastric lavage, he was given olive oil, then sorbitol. In AlP poisoning cases, rapid transfer to a treatment center; no gastric lavage, and paraffin use; the rapid analysis of arterial blood gas; laboratory tests to evaluate sodium; potassium, calcium, and magnesium; electrocardiography, and matters, like antacid administration can be of the main approaches [26-28]. However, we adopted a different approach in our study. This approach was also used in another case in the same hospital, as reported in our previous case report of AlP poisoning. In our approach, sodium bicarbonate $(50 \mathrm{cc}$ ) and aloe vera syrup (1-2 L) were used for the first day after gastric lavage.

\section{Conclusion}

There exist wide variations in the concentration of electrolytes, bicarbonate, and blood glucose; however, these can be indicative of the severity of poisoning and may significantly impact treatment planning in patients with AlP poisoning. Accordingly, it is recommended that patients with acute AlP intoxication may profit from the co-administration of insulin-glucose (which increases glucose entry into the cells) and thoroughly monitor serum corticosteroids and other electrolytes, especially magnesium and calcium, as well as their association with blood glucose levels. Thus, the role of this drug regimen in the treatment of such poisonings is recommended to be determined.

\section{Ethical Considerations}

\section{Compliance with ethical guidelines}

All ethical principles of reporting individual case information are considered in this article. No informative data that could lead to patient identification are presented. Patient confirmed this study to be published.

\section{Funding}

This study was supported by the Jahrom University of Medical Sciences.

\section{Author's contributions}

Conceptualization: Masihallah Shakeri, Heshmatollah Shakeri, and Mahdi Foroughian; Treatments and writing original draft: Davood Soroosh, Navid Kalani, and Naser Hatami; Writing - review \& editing: All authors.

\section{Conflict of interest}

The authors declared no conflicts of interest.

\section{Acknowledgements}

We would like to thank the Clinical Research Development Unit of Peymanieh Educational and Research and Therapeutic Center of Jahrom University of Medical Sciences for providing facilities for this work.

\section{References}

[1] Mostafazadeh B. Aluminium phosphide poisoning. Toxicity Drug Testing. 2012; 15:345-60. https:// www.intechopen.com/ 
books/toxicity-and-drug-testing/aluminium-phosphide-poisoning

[2] Moghadamnia AA. An update on toxicology of aluminum phosphide. DARU J Pharm Sci. 2012; 20(1):25. [DOI:10.1186/2008-2231-20-25] [PMID] [PMCID]

[3] Singh S, Bhalla A. Aluminum phosphide poisoning. J Mahatma Gandhi Inst Med Sci. 2015; 20(1):15-9. [DOI:10.4103/09719903.151721]

[4] Hasabo G. Aluminum Phosphide, A Serious killer in Egypt. J Forensic Toxicol Medicoleg Anal. 201; 1(1):6-7. [DOI:10.13107/ jbst.2250-06xx.104]

[5] Vikrant S, Gupta D, Singh M. Epidemiology and outcome of acute kidney injury from a tertiary care hospital in India. Saudi J kidney Dis Transpl. 2018; 29(4):956-66. [DOI:10.4103/13192442.239633] [PMID]

[6] Etemadi-Aleagha A, Akhgari M, Iravani FS. Aluminum phosphide poisoning-related deaths in Tehran, Iran, 2006 to 2013. Medicine (Baltimore). 2015; 94(38):e1637. [DOI:10.1097/ MD.0000000000001637] [PMID] [PMCID]

[7] Alinejad S, Zamani N, Abdollahi M, Mehrpour O. A narrative review of acute adult poisoning in Iran. Iran J Med Sci. 2017; 42(4):327-46. [PMID] [PMCID]

[8] Sulaj Z, Drishti A, Çeko I, Gashi A, Vyshka G. Fatal aluminum phosphide poisonings in Tirana (Albania), 2009-2013. DARU J Pharm Sci. 2015; 23(1):8. [DOI:10.1186/s40199-015-0090-0] [PMID] [PMCID]

[9] Aronson JK. A worldwide yearly survey of new data in adverse drug reactions. Amesterdam: Elsevier; 2011. https:// www.sciencedirect.com/bookseries/side-effects-of-drugs-annual/vol/33/suppl/C

[10] Hashemi-Domeneh B, Zamani N, Hassanian-Moghaddam H, Rahimi M, Shadnia S, Erfantalab P, et al. A review of aluminium phosphide poisoning and a flowchart to treat it. Arch Hig Rada Toksikol. 2016; 67(3):183-93. [DOI:10.1515/aiht-201667-2784] [PMID]

[11] Ahmad A, Imran Z, Asad U. The trend of acute poisoning cases presented to the emergency department of a teaching hospital. World J Pharm Med Res. 2019; 5(7):249-52. https:/ / www.researchgate.net/publication/339088337_THE_ TREND_OF_ACUTE_POISONING_CASES_PRESENTED TO THE_EMERGENCY_DEPARTMENT_OF_A_TEACHING_HOSPITAL

[12] Sciuto AM, Wong BJ, Martens ME, Hoard-Fruchey H, Perkins MW. Phosphine toxicity: A story of disrupted mitochondrial metabolism. Ann N Y Acad Sci. 2016; 1374(1):41-51. [DOI:10.1111/nyas.13081] [PMID] [PMCID]

[13] Yan H, Xiang P, Zhang S, Shen B, Shen M. Diagnosis of aluminum phosphide poisoning using a new analytical approach: Forensic application to a lethal intoxication. Int J Legal Med. 2017; 131(4):1001-7. [DOI:10.1007/s00414-017-1562-1] [PMID]

[14] Demir U, Hekimoğlu Y, Aşırdizer M, Etli Y, Kartal E, Gümüş $\mathrm{O}$. A case who died due to the suicidal intake of aluminum phosphide. Cumhuriyet Tip Dergisi. 2017;39(1):458-65. [DOI:10.7197/cmj.v39i1.5000206760]

[15] Mashayekhian M, Hassanian-Moghaddam H, Rahimi M, Zamani N, Aghabiklooei A, Shadnia S. Elevated carboxyhaemoglobin concentrations by pulse co-oximetry is associated with severe aluminium phosphide poisoning. Basic Clin Pharmacol Toxicol. 2016; 119(3):322-9. [DOI:10.1111/bcpt.12571] [PMID]

[16] Mirakbari SM. Hot charcoal vomitus in aluminum phosphide poisoning-A case report of internal thermal reaction in aluminum phosphide poisoning and review of literature. Indian J Anaesth. 2015; 59(7):433-6. [DOI:10.4103/0019-5049.160952] [PMID] [PMCID]

[17] Hugar BS, Praveen S, Hosahally JS, Kainoor S, Shetty AR Gastrointestinal hemorrhage in aluminum phosphide poisoning. J Forensic Sci. 2015; 60 Suppl 1:S261-3. [DOI:10.1111/15564029.12588] [PMID]

[18] Mehrpour O, Gurjar M. Cardiogenic shock: The main cause of mortality in acute aluminum phosphide poisoning. Indian J Crit Care Med. 2017; 21(4):246-7. [DOI:10.4103/ijccm.IJCCM_97_17] [PMID] [PMCID]

[19] Karimani A, Mohammadpour AH, Zirak MR, Rezaee R, Megarbane B, Tsatsakis A, et al. Antidotes for aluminum phosphide poisoning-An update. Toxicol Rep. 2018; 5:1053-9. [DOI:10.1016/j.toxrep.2018.10.009] [PMID] [PMCID]

[20] Surjushe A, Vasani R, Saple DG. Aloe Vera: A short review. Indian J Dermatol. 2008; 53(4):163-6. [DOI:10.4103/00195154.44785] [PMID] [PMCID]

[21] Mahor G, Ali SA, Parveen N. Aloin from Aloe Vera leaves: A potential natural aluminium detoxificant. Biosci Biotech Res Comm. 2019, 12(2):531-538. [DOI:10.21786/bbrc/12.2/41]

[22] Singh KR. Studying corrosion inhibitory effect of Aloe Vera juice on stainless steel used for orange juice storage. Int J Basic Appl Chem Sci. 2012; 2(3):48-55. https://www.cibtech.org/JCHEMICAL-SCIENCES/PUBLICATIONS/2012/Vol_2 No_3/09-002...Rajesh...Inhibition...Juice...48-55.pdf

[23] Rayat Dost E, Foroughian M, Shakeri M, Shakeri H, Abiri S Saving from fatal effect of aluminum phosphide (rice tablet): A case report. Amb Sci. 2019; 6(1):40-2. https://scholar.google. $\mathrm{com} /$ scholar?hl=fa\&as_sdt $=0 \% 2 \mathrm{C} 5 \& \mathrm{q}=$ Saving + from + Fatal $+\mathrm{E}$ ffect + of + Aluminum + Phosphide $+\% 28$ Rice + Tablet $\% 29 \% 3 \mathrm{~A}+\mathrm{a}+$ Case+Report\&btnG $=$

[24] Singh S, Dilawari JB, Vashist R, Malhotra HS, Sharma BK Aluminium phosphide ingestion. Br Med J (Clin Res Ed). 1985 290(6475):1110-1. [DOI:10.1136/bmj.290.6475.1110] [PMID] [PMCID]

[25] Karimi R, Taheri H. [Report of two successful treatment of rice poisoning (Persian)]. J Babol Univ Medical Sci. 2007; 9(1):58-62. http://jbums.org/article-1-3048-fa.html

[26] Siwach SB, Singh P, Ahlawat S, Dua A, Sharma D. Serum \& tissue magnesium content in patients of aluminium phosphide poisoning and critical evaluation of high dose magnesium sulphate therapy in reducing mortality. J Assoc Physicians India. 1994; 42(2):107-10. [PMID]

[27] Schonwald S, Ellenhorn MJ. Medical toxicology: A synopsis and study guide. Philadelphia: Lippincott, Williams and Wilkins; 2001. https:/ / books.google.com/books/about/Medical_Toxicology.html?id=F9j4AQAACAAJ

[28] Rahbar Taramsary M, Orangpoor R, Zarkami T, Palizkar M, Mousavian SA. [Survey patients poisoned with aluminum phosphide (rice tablet) (Persian)]. Jour Guilan Uni Med Sci. 2005; 14(56):42-7. http://journal.gums.ac.ir/article-1-494-en. $\mathrm{html}$ 